\title{
Nuclear Politics of Denial: South Africa and the Additional Protocol
}

\author{
Joelien Pretorius ${ }^{1}$ \\ Department of Political Studies, University of the Western Cape, EMS Building Room 4.01.4, \\ Private Bag X17, Bellville, 7535, South Africa \\ (E-mail: jpretorius@uwc.ac.za)
}

Received 3 May 2012; accepted 25 July 2012

\begin{abstract}
South Africa was one of the first states to conclude an Additional Protocol with the International Atomic Energy Agency (IAEA) in 2002, allowing the IAEA greater right of access to safeguard nuclear activities and material. In light of this, some observers in the arms control community find it odd that South Africa's representatives at the Nuclear Suppliers Group (NSG) would be the main objectors to making the conclusion of an Additional Protocol a precondition for states wishing to import uranium enrichment and reprocessing technology (classified as sensitive nuclear technology and material). The South African objection should be viewed as only the most recent in a series of objections to measures that may seem obviously in line with nuclear non-proliferation. This emerging pattern in South Africa's nuclear diplomacy and, more specifically, the objection to the Additional Protocol condition are related to its membership in the Non-Aligned Movement (NAM) and can be investigated through the lens of a politics of denial. Denial is the act of saying "no", but it is also in psychological parlance the unconscious thought process manifesting a refusal to acknowledge the existence of certain unpleasant aspects of external reality. It will be argued that South Africa's opposition to the Additional Protocol condition can be explained in the context of two instances of denial: (i) a perceived denial by the nuclear haves of what the Nuclear Non-Proliferation Treaty codifies as an inalienable right to peaceful nuclear technology something that South Africa is cautious to be complicit in; and (ii) the nuclear weapon states' denial (the psychological meaning) of the unpleasant reality of a hypocritical nuclear order - something that South Africa wants to expose or at least something with which to engage to limit the effects for itself and other NAM members. The politics of denial does not yield to a pragmatist/utopian dichotomy in the nuclear realm, but instead reveals the dialectic nature of realism and idealism in nuclear politics, especially as reflected in South Africa's nuclear diplomacy.
\end{abstract}

\section{Keywords}

Nuclear Suppliers Group; Additional Protocol; nuclear diplomacy; South Africa; Non-Aligned Movement; uranium enrichment; spent fuel reprocessing; sensitive nuclear transfers; Brazilian-Argentine Agency for Accounting and Control of Nuclear Materials (ABACC)

1) Joelien Pretorius is an associate professor in the Department of Political Studies at the University of the Western Cape and also a member of the Pugwash Conferences on Science and World Affairs (South Africa Chapter). She obtained a PhD at the University of Cambridge in 2006, investigating how the revolution in military affairs has influenced post-apartheid defense thinking in South Africa. 
South Africa was one of the first states to conclude an Additional Protocol with the International Atomic Energy Agency (IAEA) in 2002, strengthening the latter's authority to safeguard nuclear activities, material and facilities. In light of this, some observers in the arms control community found it odd that South Africa's representatives at the Nuclear Suppliers Group (NSG) were by 2009 the main objectors to making the conclusion of an Additional Protocol a condition for recipient states wishing to import uranium enrichment and spent fuel reprocessing (ENR) technology. Although these stricter guidelines have in the meanwhile been adopted by consensus, South Africa insisted on changes in the draft text of the new NSG guidelines. South Africa's controversial stance on this matter should be viewed as only the most recent in a series of objections to measures that may seem "obviously sensible" for nuclear non-proliferation. This emerging pattern in South Africa's nuclear diplomacy and, more specifically, South Africa's objection to the Additional Protocol condition can be investigated through the lens of a politics of denial that is closely linked to South Africa's membership to the Non-Aligned Movement (NAM). Denial is the act of saying "no" (a negative reply or rejection of a request), but it is also, in psychological parlance, the unconscious thought process manifesting a refusal to acknowledge the existence of certain unpleasant aspects of external reality. It will be argued that South Africa's saying "no" to the Additional Protocol condition for receiving ENR technology can be explained in the context of two other instances of denial: (i) a perceived denial by the nuclear haves of what the Treaty on the Non-Proliferation of Nuclear Weapons (1970) codifies as an inalienable right to peaceful nuclear technology - something that South Africa is cautious to be complicit in; and (ii) the nuclear weapon states' denial (the psychological meaning) of the unpleasant reality of a hypocritical nuclear order - something with which South Africa should engage not only as a NAM member, but in the course of pursuing its own security and commercial interests as well.

An article analyzing and explaining South Africa's position in the NSG on the Additional Protocol as a condition of supply for ENR technology may seem like flogging a dead horse, but is nevertheless important for the following reasons. The NSG's meetings are opaque; the press briefings after its meetings sometimes only reveal the place of the next meeting and very little is said about the discussions that precede a 'consensus' decision; however, other times information is leaked from the meetings and such leaks could well have the intent to push discussions inside the NSG in certain directions. ${ }^{2}$ In the case at hand, as negotiations were

\footnotetext{
2) For example, the 2008 confidential draft text of the NSG guidelines was leaked (McGoldrick 2011: Appendix 2). Confidential pieces of information have also leaked on the Arms Control Wonk blog run by Jeffrey Lewis, Director of the East Asia Nonproliferation Program at the James Martin Center for Nonproliferation Studies at the Monterey Institute of International Studies. For example, it was on this blog that Lewis noted that the draft text of the NSG's new guidelines on ENR would only allow regional agreements concluded before a specific year (Lewis 2011b). The inclusion of a specific year would restrict
} 
progressing, several US Arms Control blogs and think tank briefs mentioned South Africa's objection to the Additional Protocol; but there was no real attempt to explain South Africa's position (Hibbs 2010; Carlson 2011; Lewis 2011a). Rather, South Africa's objection was deemed as odd, an anomaly for a country that prides itself on its own nuclear disarmament and non-proliferation credentials. The article therefore in retrospect attempts what the US bloggers and think tanks failed to do, namely to explain the rationale for South Africa's position. It will go about this by first outlining what the Additional Protocol is and how it relates to the Non-Nuclear Weapon States' perceived inalienable right to civil nuclear technology. The article will then proceed to the role of the NSG in setting guidelines for nuclear exports, and in this case review the key moments in negotiating stricter guidelines for the export of sensitive nuclear technology. The article will then turn to South Africa's position, framing its objection to the Additional Protocol and later to a controversial exception for Brazil and Argentina in the context of South Africa's NAM membership. Finally, the article will draw some conclusions about the politics of denial as it played out in this case and how South Africa was able to mediate pragmatism and principle.

\section{Article 4 of the Nuclear Non-Proliferation Treaty and the Additional Protocol}

To understand the South African position, we need to return to the so-called "grand bargain", which was negotiated in the late 1960s and codified in the Nuclear Non-Proliferation Treaty (NPT) of 1970. Nuclear Weapon States (states that had tested nuclear weapons by 1967) agreed not to provide NonNuclear Weapons States (states that had not tested nuclear weapons by 1967) with nuclear weapons or facilitate the development of these weapons and to give up their own nuclear weapons in the future (nuclear disarmament). In turn, NonNuclear Weapon States promised not to acquire or develop nuclear weapons. The inducement to give up the right to have nuclear weapons came in the form of legal assurance to Non-Nuclear Weapon States under the NPT of an entitlement (an "inalienable right") to civil nuclear technology. Article IV guarantees "the right of all parties to participate in the fullest possible exchange of equipment, materials, and scientific and technological information for the peaceful uses of nuclear energy ... with due consideration for the needs of developing areas of the world." Although the grand bargain confirmed and codified an onus on nuclear capable states to facilitate the development of nuclear energy for peaceful purposes "especially in the territory of Non-Nuclear Weapon States," Article 4 also

exceptions to the Additional Protocol condition of supply to the Brazilian-Argentine Agency for Accounting and Control of Nuclear Materials (ABACC) and the European Atomic Energy Community (EURATOM). The year was removed from the final text. 
codifies a nuclear export norm that originates from U.S. law, namely to restrict nuclear cooperation in the name of nuclear weapons non-proliferation to peaceful purposes only. ${ }^{3}$

The application of the export norm opens up a space for the "politics of denial" inasmuch as suppliers can say "no" to requests from Non-Nuclear Weapon States - an act aptly labelled "license denial." States wishing to receive nuclear technology and material must assure nuclear suppliers of intentions of peaceful use and non-diversion to military purposes. ${ }^{4}$ The verification of peaceful purposes is done through International Atomic Energy Agency (IAEA) safeguards, defined as an "extensive set of technical measures by which the IAEA Secretariat independently verifies the correctness and the completeness of the declarations made by States about their nuclear material and activities" (IAEA n.d.: III.A.5). Prior to the NPT, IAEA safeguards were applied to specific material and equipment only and not to the entirety of a state's nuclear activity as described in an Information Circular identified as INFCIRC/66/Rev.2. However, a comprehensive safeguards system was devised to implement the NPT and is set out in IAEA document INFCIRC/153 (corrected). Comprehensive safeguards are "full scope" in nature in that states are expected to declare and allow for IAEA verification, which may include measures such as inspections or monitoring all present and future nuclear activities.

The discovery in 1990 of the advance development of Iraq's clandestine nuclear weapons program, virtually under the noses of IAEA inspectors as well as accounting discrepancies in North Korea's nuclear activities discovered in 1992 led to a campaign to strengthen the safeguard system. The aim was to expand the IAEA's reach from designated control and measuring points at declared nuclear facilities to be able to detect undeclared or covert nuclear activities (Hibbs 2010). This came in the form of an Additional Protocol to states' safeguards agreements. The model Additional Protocol, adopted by the IAEA Board of Governors in 1997, has two features: it broadens the scope of the declaration that a state must make about activities that have the potential to contribute to nuclear weapons development, and it provides the IAEA with complementary access rights, including the right to inspect undeclared locations (Hirsch 2004: 143, Hibbs 2010). As Kimball (2012) notes the Additional Protocol reshapes the IAEA's safeguards regime "from a quantitative system focused on accounting for known quantities of materials and monitoring declared activities to a qualitative system aimed at gathering a comprehensive picture of a state's nuclear and nuclear-related activities, including all nuclear-related imports and exports." Instead of putting only certain facilities under safeguards, in a sense a state as a whole is put under safeguards, thus transforming IAEA inspectors "from accountants to detectives".

\footnotetext{
3) For example, see the US Atomic Energy Act of 1954.

4) For the proliferation risks attached to civilian nuclear programs, see Nassauer 2006.
} 
(Hirsch 2004; Marzo 2012). Although the Additional Protocol is a voluntary agreement, as its name implies, additional (or supplementary) to NPT safeguards, and not an NPT requirement, the IAEA considers it essential to verify, not only the non-diversion of declared nuclear material by a state as the Comprehensive Safeguards Agreements do, but also the absence of undeclared nuclear material and activities (IAEA 2003).

In 2004, the covert activities of Pakistani nuclear scientist, A.Q. Kahn, were exposed to the horror of many in the non-proliferation community. Subsequently, the Bush Administration increased pressure to make the Additional Protocol the standard (as opposed to an option) for safeguards. In a speech at the National Defense University former President Bush made seven proposals to strengthen measures that prevent the spread of weapons of mass destruction, one among them being that "only states that have signed the Additional Protocol be allowed to import equipment for their civilian nuclear programs" (The White House, 2004). He also asserted: "The world's leading nuclear exporters should ensure that states have reliable access at reasonable cost to fuel for civilian reactors, so long as those states renounce enrichment and reprocessing. Enrichment and reprocessing are not necessary for nations seeking to harness nuclear energy for peaceful purposes. The... Nuclear Suppliers Group should refuse to sell enrichment and reprocessing equipment and technologies to any state that does not already possess full-scale, functioning enrichment and reprocessing plants" (ibid.). The speech set off a major US diplomatic effort in the NSG to tighten up its guidelines for ENR transfers. ${ }^{5}$

\section{The NSG and the Additional Protocol}

\section{The NSG's Role in the Nuclear Non-proliferation Regime}

The Nuclear Suppliers Group is an international organization consisting of 46 of the world's top nuclear exporting countries. The group was founded in 1975 after it became known that India covertly built a nuclear weapons program on the back of its civil nuclear program using technology acquired from abroad for its civilian program. The rationale for the NSG's existence is thus to ensure that members' exports do not add to nuclear proliferation, but are used for peaceful purposes only in the context of Non-Nuclear Weapon States' inalienable right to civilian nuclear technology, as guaranteed by the NPT. Because the NSG has the leverage of denying states access to nuclear technology through its guidelines,

5) The diplomatic effort also extends to the US' bilateral nuclear relations. The US either has or is in the process of negotiating nuclear cooperation agreements with a number of countries that requires the latter to conclude an Additional Protocol as condition of cooperation as well as to forego possession of sensitive nuclear facilities, such as enrichment and reprocessing capabilities. See Kerr et al. 2011: 17-18. 
the organization is often used as a forum and channel to develop, diffuse and enforce norms and standards in the area of non-proliferation (Pretorius 2011). This is especially true for norms that would be either controversial to introduce or promote in other (larger) forums, such as the NPT review conferences; or impossible to enforce in the absence of some states' membership in other key non-proliferation treaties. A case in point is the NSG's requirement for recipients to have a comprehensive safeguards agreement in place before nuclear exports can occur; for example, France was an NSG member before it acceded to the NPT. It was under the guidelines of the NSG, and not of the NPT, that it could only export to states with a comprehensive safeguards agreement.

Although the emphasis is usually placed on the NSG's role to universalize nuclear export and non-proliferation norms, it would be naïve to not consider this role in the commercial and economic context of nuclear trade competition. Any application of nuclear trade restrictions by one state to prevent a state suspected of having proliferation intentions, if done unilaterally, can not only be offset if the suspected state can simply turn to another nuclear supplier, but the state applying such restrictions loses a share of the nuclear market to another supplier as well. Nuclear trade restrictions and their application are thus as much an issue of national economic interest as they are of interest to international and national security. The NSG's less acknowledged role is exactly this, to ensure that the negative impact on market access of nuclear trade restrictions is borne by all nuclear suppliers. Often referred to as the "No undercutting" principle, as outlined in the Memorandum of Understanding on Implementation of the Guidelines for Transfers of Nuclear-Related Dual-Use Equipment, Material and Related Technology (Paragraph 4) agreed in Warsaw in 1992. The principle essentially aims to level the playing field among suppliers (Joyner 2011: 55). A state is obliged to notify other NSG members if decides not to authorize a nuclear transfer. The notification of denial (of license) is reviewed by the state that issued it after three years and other NSG members are required not to authorize "essentially identical technology" to the state that was refused in that period. If an NSG member considers supplying such a state, it must consult with the state that issued the denial notification and notify other NSG members if it decides to go ahead (Stockholm International Peace Research Institute n.d.).

The Bush Administration's efforts to restrict access to ENR technology in the NSG and the debates and negotiations that followed can thus also be understood in the context of each supplier thinking not only about promoting the principle of non-proliferation, but the impact of stricter guidelines on their national nuclear industries and global market share vis-à-vis other current and future suppliers. As such, states outside the NSG have occasionally raised suspicions of the NSG's motives, referring to it as a nuclear cartel. This point will be returned to below. 


\section{The NSG's Original Guidelines for ENR Technology}

The guidelines that the NSG has developed distinguish between, on the one hand, nuclear transfers such as exports especially designated for nuclear use, and on the other hand, transfers of nuclear-related dual use equipment, materials, software and related technologies. The focus of this article is on (the denial of) transfers of sensitive nuclear technology and material, the guidelines of which can be found in INFCIRC/254, Part 1, governing the export of nuclear material, reactors and related equipment and non-nuclear material for reactors, plant and material for reprocessing, enrichment and conversion of nuclear material as well as for the making of fuel and heavy water and the associated technologies. The original guidelines for ENR transfer per Paragraphs 6 and 7 of INFCIRC/254, Part 1 read:

\section{Special controls on sensitive exports}

6. Suppliers should exercise restraint in the transfer of sensitive facilities, technology and material usable for nuclear weapons or other nuclear explosive devices. If enrichment or reprocessing facilities, equipment or technology are to be transferred, suppliers should encourage recipients to accept, as an alternative to national plants, supplier involvement and/or other appropriate multinational participation in resulting facilities. Suppliers should also promote international (including IAEA) activities concerned with multinational regional fuel cycle centers.

\section{Special controls on export of enrichment facilities, equipment and technology}

7. For a transfer of an enrichment facility, or technology therefor, the recipient nation should agree that neither the transferred facility, nor any facility based on such technology, will be designed or operated for the production of greater than $20 \%$ enriched uranium without the consent of the supplier nation, of which the IAEA should be advised.

These guidelines are not very specific or restrictive. Paragraph 6, for example, asks only that members "exercise restraint." At its 14th plenary meeting in 2004, the NSG "noted with deep concern the discovery of elements of a covert international proliferation trafficking network, through which sensitive nuclear related equipment had found its way to Libya" (NSG 2004). As a result, at the next plenary meeting the NSG agreed to prioritize continued discussions to strengthen its guidelines regarding the supply of enrichment and reprocessing technologies (ERT). "Continued discussions" in this context indicates that consensus could not be achieved. Most NSG members rejected Bush's proposal that ENR transfers should be banned except to those states that already had full-scale functioning plants. For four years the United States' insistence on this ban stalled "discussions" until the United States finally accepted a more flexible, criteria-based approach to ENR transfers in 2008 (McGoldrick 2011: 15). Such an approach would stipulate criteria that prospective recipients of ENR must meet before NSG members can export to them. The discussion then became one of what criteria should be included and how they should be worded. A distinction is made between 
"objective" and "subjective" criteria. For example, the former includes that recipients must be NPT members, in full compliance with the treaty, comply with international standards of physical protection and safety of nuclear facilities, and so forth. The latter asks supplier states to consider the impact of ENR transfers on the stability and security in the recipient state and how "credible and coherent" the rationale for the state's pursuit of ENR technology is (ibid.: 13).

\section{The Brazil-Argentina Exception}

One of the initial "objective" criteria included that recipient states had to have an Additional Protocol in place. Brazil, Argentina and South Africa objected to this criteria. ${ }^{6}$ Neither Brazil nor Argentina has concluded an Additional Protocol or seems to have an intention to do so; this grounded their objection to making the Additional Protocol a condition of supply, which would in a sense force them to conclude an Additional Protocol or be ostracized in the nuclear export regime. Brazil is most vocal about its refusal to conclude an Additional Protocol. Although this refusal is driven mainly by officials from the Department of Defense, various Brazilian officials have given reasons for Brazil's position, such as the Nuclear Weapon States' slow pace of disarmament, regarding the Additional Protocol as superfluous in the light of Brazil's established constitutional and treaty commitments not to develop nuclear weapons, and even asserting that the Additional Protocol is a form of industrial espionage by developed states (Hibbs 2011:3).

It is likely that Argentina shares these reasons and at least two others that have not been vocalized as explicitly. The first relates to these countries' checkered nuclear past and the second relates to the sense that they can use their bilateral nuclear safeguard system to avoid signing an Additional Protocol. There were concerns up to the 1990s that both Brazil and Argentina had nuclear weapons programs, although they never had nuclear weapons as such. Should these states conclude an Additional Protocol, they would have to disclose high-level radioactive waste inventories, which in turn would expose their past undeclared nuclear activities and may confirm the status of their nuclear weapons programs prior to the 1990s (ibid.: 4).

As part of larger democratization processes, Brazil and Argentina renounced nuclear weapons, and among other non-proliferation measures, signed a bilateral agreement confirming the exclusively peaceful use of nuclear energy by both states in 1991. The Brazilian-Argentine Agency for Accounting and Control of Nuclear Materials (ABACC) was established under this agreement and is responsible for the administration and application of the Common System of Accounting and Control (SCCC). The SCCC is described as "a full-scope safeguards system applied to all nuclear activities covering all nuclear materials in both countries"

\footnotetext{
6) Although there were criteria to which other states objected to as well, at this point the article will be confined to the objection to making the Additional Protocol a condition of ENR supply.
} 
(ABACC n.d.) Brazil, Argentina, ABACC and the IAEA subsequently also signed the Quadripartite Agreement (see INFCIRC 435) which entered into force in 1994 and is in essence a standard NPT comprehensive safeguards agreement.

By 2008 Brazil and Argentina were able to negotiate an agreement with most Nuclear Suppliers Group members that effectively exempted them from the Additional Protocol requirement by formulating the related criteria for enrichment and reprocessing (ENR) technology transfers (paragraph 6(a)(ii) of INFCIRC 254/Part I, 20 November 2008) to read that suppliers should not authorize ENR transfers if the recipient does not meet, among others, the following criteria:

(ii) Has signed, ratified and is implementing a comprehensive safeguards agreement with the IAEA, and has in force an Additional Protocol or has signed, ratified and is implementing a regional arrangement approved by the IAEA which operates to achieve the same objective by providing confidence in the peaceful nature of civilian nuclear programs. ${ }^{7}$

Only two regional arrangements qualified - ABACC and Euratom. Euratom has concluded an Additional Protocol. The wording thus really only applies to ABACC and has been described as highly problematic and illogical. Although the wording implies equivalence between the Additional Protocol and ABACC, the former provides the IAEA with far-reaching inspection rights, whilst the latter is an institution with verification functions that do not reflect the new philosophy of safeguards introduced by the Additional Protocol as described above (Hibbs 2010: 4). In essence it seems that some NSG members were willing to compromise on the equity principle by making an exception for Brazil and Argentina in return for these two states dropping their objection to the Additional Protocol to be a condition of supply for all other Non-Nuclear Weapon States.

\section{South Africa's Position}

South Africa's initial position was to object to making the Additional Protocol a condition of supply (ibid. 2011: 2). For most of the negotiation of the draft text this was diplomatically tenable, inasmuch as it was assumed that Brazil and Argentina's refusal to conclude an Additional Protocol 'covered' the South African position in the NSG. However, when a deal was struck with Brazil and Argentina to exempt them from the Additional Protocol condition, South Africa was isolated diplomatically. It was not difficult to put pressure on South Africa to conform by portraying the country as obstructionist to an obviously sensible move for non-proliferation. For example, John Carlson, director-general of the

7) The "clean text," referring to the 2008 draft guidelines, was published in McGoldrick (2011). Jeffrey Lewis, Director of the East Asia Nonproliferation Program at the James Martin Center for Nonproliferation Studies at the Monterey Institute of International Studies, noted his surprise about this given that the draft text was confidential. 
Australian Safeguards and Non-Proliferation Office until 2010, wrote in a letter to the editor of Arms Control Today (March 2011): "The NSG has developed compromise language that appears to meet the Argentine-Brazil situation. Now, however, it seems South Africa is the chief obstacle. This is surprising, considering South Africa was one of the early states to conclude an additional protocol in 2002" (Carlson 2011).

It seems that the South Africans consequently decided on a change in strategy. Ambassador Abdul Minty, South Africa's chief representative at the NSG, gave the reason in 2011 for South Africa's continued objection to the 2008 "clean text" as the text's exception for Argentina and Brazil and not an objection to the Additional Protocol as such. ${ }^{8}$ The South Africans deemed it hypocritical to ask all Non-Nuclear Weapon States to have an Additional Protocol in place, but then to allow two of its own in the ranks of the NSG to operate outside this rule. The result of South Africa's position was the renegotiation of the clean text so as to delete the Additional Protocol from the list of specific criteria for ENR transfers and address it in a separate paragraph to read:

(c) Suppliers will make special efforts in support of effective implementation of IAEA safeguards for enrichment or reprocessing facilities, equipment or technology and should, consistent with paragraphs 4 and 13 of the Guidelines, ensure their peaceful nature. In this regard, suppliers should authorize transfers, pursuant to this paragraph, only when the recipient has brought into force a Comprehensive Safeguards Agreement, and an Additional Protocol based on the Model Additional Protocol or, pending this, is implementing appropriate safeguards agreements in cooperation with the IAEA, including a regional accounting and control arrangement for nuclear materials, as approved by the IAEA Board of Governors.

This text was accepted at the NSG's plenary meeting in Noordwijk, the Netherlands on 24 June 2011. According to Hibbs (2011: 3) "the main difference between the 'clean text' and the final new guidelines is that the former obligates ENR recipients to have an Additional Protocol and that the latter stipulates that suppliers should themselves require it." There are different interpretations of the "pending this [bringing into force an Additional Protocol]" clause. The Brazilians do not see this as an indication that the Quadripartite Agreement must be supplemented with an Additional Protocol, whilst the American position is that the clause "was a way of saying that the NSG would continue to review the situation with respect to the status of adherence to the additional protocol" (Horner 2011).

8) This response was given to the author upon asking Amb. Minty why South Africa objected to the Additional Protocol as condition to supply in a personal interview, Cape Town, 31 May 2011. 


\section{The Politics of Denial: Restricting Article IV Rights}

As noted above, the Nuclear Suppliers Group, by its very nature, is a space where a politics of denial will play itself out. The language of the guidelines on ENR transfers reflects the tone of denial (refusal or "saying no"): “... suppliers should not authorize the transfer of enrichment and reprocessing facilities, and equipment and technology therefore if the recipient does not meet, at least, all of the following criteria...", rather than a permissive tone that would read: "... suppliers should authorize the transfer... to a recipient that meets the following criteria...”.

South Africa got involved in the politics of denial when it initially objected to the Additional Protocol as a condition of supply. This position seemed to contradict Ambassador Minty's statement at the Nuclear Weapons Non-Proliferation Treaty (NPT) 2010 Review Conference on the matter: "In both the 1995 and 2000 Conferences, NPT States Parties already committed to the strengthening of IAEA safeguards. Whilst the Additional Protocol is a voluntary measure, we could recognize its importance as a confidence building measure, especially with regard to those States with advanced nuclear programs and facilities. The Additional Protocol is an indispensable instrument, which enables the IAEA to provide credible assurances regarding the absence of undeclared nuclear material" (Minty 2010). However, the objection to the Additional Protocol makes sense in the context of South Africa's membership of the Non-Aligned Movement.

South Africa is one of only two NAM members in the NSG - Belarus being the other. ${ }^{9}$ With a rather advanced nuclear industry and the demonstrated ability to develop nuclear weapons, South Africa is recognized as a developed state in the field of nuclear technology. In 1994, following South Africa's democratic transition, the new government chose to use South Africa's status as developed nuclear state with membership of the NAM to create a middle power identity of a bridge builder or mediator among the nuclear "haves" and "have nots". The most prominent example of this is South Africa's role at the 1995 Review and Extension Conference to extend the NPT indefinitely. At the time strong opposition to the proposal of indefinite extension came from some NAM members, who wanted among other factors to renegotiate more definite timelines for the Nuclear Weapon States' disarmament obligations under Article VI. Over time South Africa's nuclear diplomacy has shifted more towards non-alignment sometimes by reflecting "support" for fellow NAM members and sometimes in taking an independent position on a matter under discussion (Leith \& Pretorius 2010). There is, however, a sense that South Africa represents the interests of the Non-Aligned Movement in the NSG and, if it diverges from expressed

9) Brazil is an observer to the NAM, but not an official member. 
NAM positions, the country at least needs to be able to justify this divergence to NAM members.

Formed during the Cold War to give a voice to so-called Third World countries, the NAM's historical cause was two-fold: promotion of self-determination and economic development in a world order that was skewed against the Third World. This legacy of anti-colonialism and struggle against economic exploitation and dependency still influences the "nuclear narrative" of the NAM, which regards restrictions (in addition to those agreed to explicitly in the NPT) on nuclear transfers as "unfair, unnecessary or disproportionately burdening nonnuclear weapon states" (Yew 2011: 3). Some find it a naïve position that the "inalienable right" is conditional on proof of peaceful use and this can only be established by the Additional Protocol, which therefore should not be seen as optional (Carlson 2011). However, the NAM sees the Additional Protocol as part of a bigger agenda to generally restrict sensitive nuclear technology to those states that already have enrichment and/or reprocessing facilities. Given the diplomatic efforts of the United States since 2004, this is not an unrealistic conclusion.

The NAM's position on restricting ENR technology is reflected in a number of statements, for example, the final document (par 88) of the NAM XI Summit in Cartagena, 18-20 October 1995 reads,

The Heads of State or Government noted with concern the growing restraint being placed on access to material, equipment and technology for peaceful uses of nuclear energy by the developed countries through imposition of ad-hoc export control regimes. These may impede the economic and social development of developing countries.

The NAM statement to the 2010 Review Conference made a similar point: "The unimpeded and non-discriminatory transfer of nuclear technology for peaceful purposes must be ensured." Quoting from the 2000 Review Conference final document, the statement continues:

... 'each country's choices and decisions in the field of peaceful uses of nuclear energy should be respected without jeopardizing its policies or international cooperation agreements and arrangements for the peaceful uses of nuclear energy and its fuel-cycle policies.' Article IV is explicit on this subject, and the NAM States Parties do not see any room for reinterpretation or setting of conditions for peaceful uses of nuclear energy. The undue restrictions currently being applied to many developing countries Parties to the NPT are regrettable and should be removed.

The sentiment expressed here is not just an entitlement to nuclear technology for peaceful purposes, but nuclear sovereignty (or nuclear self-determination) when it comes to the choices Non-Nuclear Weapon States make about their civilian programs. It manifests not only in the Additional Protocol debate, but also in NAM's rejection of multinational approaches to the fuel cycle and international fuel banks, closely linked to the ENR/Additional Protocol debate. The idea behind multinational facilities and fuel banks is that states will be granted access 
to enriched uranium and return spent fuel to be reprocessed at international facilities at reasonable costs, but must in return forego enrichment and reprocessing facilities in their territories. NAM members are reluctant to sign away their right to enrichment and reprocessing technologies. In a paper presented to the International Atomic Energy Agency (IAEA) Board of Governors in June 2009 this position was put across strongly:

\begin{abstract}
The Group, in principle, reiterates its strong rejection of any attempts aimed to discourage the pursuit of any peaceful nuclear technology on the grounds of its alleged 'sensitivity'. The Group is of the view that any proposal for the assurance of supply should not be designed in a way that discourages States from developing or expanding their capabilities in the area of the nuclear fuel cycle, nor to hamper research and development and international cooperation in the field of peaceful nuclear activities. The Group reiterates that it is the sovereign right of all States without discrimination to develop or expand their capabilities in the field of peaceful nuclear activities including the nuclear fuel cycle. The Agency should not lose its main focus on promoting the peaceful uses of nuclear science and technology, including national fuel cycle capabilities, through national capacity building and transfer of technology (McGoldrick 2011:21).
\end{abstract}

The NAM position is usually only viewed in the light of Non-Nuclear Weapon States' NPT right to peaceful nuclear technology for their domestic use as recipients (or first order benefits); however, some NAM states view access to nuclear technology also from the commercial perspective of suppliers that should be allowed to develop nuclear industries that can share in the expected lucrative global market that a nuclear energy renaissance may bring (second order benefits). States with significant natural uranium deposits and the ambition and ability to become technology leaders, like South Africa, do not want their right to value added enrichment denied. South African Minister of Minerals and Energy expressed this sentiment when the country refused to join the United States led Global Nuclear Energy Partnership (GNEP, since re-named the International Framework for Nuclear Energy Cooperation). Although Bulelwa Sonjica, South Africa's Minister of Minerals and Energy at the time, said that fuel would be distributed to countries under the GNEP, South Africa "has taken a decision to beneficiate its minerals... in other words, to end-value the minerals in South Africa and that would include uranium" (AFP 2007). She also noted that exporting uranium only to get it back refined, instead of enriching it in South Africa, would be in conflict with South Africa's national policy.

There is a tendency by some analysts and officials to characterize the NAM position as simply that of some NAM "spoilers" dogmatically running "the nuclear debate as a confrontation between the developed and developing world" (Yew 2011: 2). The reality is more nuanced than this. Not only are the opinions within the NAM more diverse and the general practice of non-proliferation principles by the majority of NAM members more robust than for which they are given credit, but NAM members are also not the only states to raise concerns about restrictions to Article IV. Canada, Spain, South Korea, the Netherlands and Switzerland 
all expressed concerns about how ENR transfer restrictions may impact their nuclear industries and future commercial interest, specifically, and the right of Non-Nuclear Weapon States under Article IV, generally (McGoldrick 2011: 16). One of the restrictions entailed "black boxing" enrichment technology, such as a supplier building plants and sensitive equipment in such a way that they cannot be replicated by the recipients, who receive only sufficient know-how to operate the plant (Kerr et al. 2011: 11). Canada, Switzerland and Spain were concerned that black-boxing would deny the option of importing or sharing centrifuge technology that their industries could upgrade over time for commercial benefit (McGoldrick 2011: 19).

Another political and commercial concern that some developed Non-Nuclear Weapon States share with the Non-Aligned Movement is that states in good standing with the IAEA and their NPT obligations should not be denied enrichment options and suppliers should not be denied a legitimate market (McGoldrick 2011: 21). In South Africa's considerations of the Additional Protocol as a condition of supply, Egypt, a fellow member of both NAM and the African Union, is a case in point of a state that abides by its NPT obligations and is in good standing with the IAEA, but would be denied ENR transfers because it does not have an Additional Protocol in place. It is also unlikely that Egypt will have one in the foreseeable future. Egypt has decided not to commit to any additional nonproliferation arrangements, including an Additional Protocol, until the issue of Israel's nuclear weapons program receives international attention. The changes to the draft text, on which South Africa insisted, reflects a compromise inasmuch as the new guideline would not only exempt Brazil and Argentina pending their conclusion of Additional Protocols, but, in theory, leave open a way for South Africa and Egypt to conclude an ABACC type regional accounting and control arrangement as well. If approved by the IAEA Board of Governors, such an arrangement could arguably allow the export of sensitive material on the same grounds as for Brazil and Argentina. ${ }^{10}$

\section{The Politics of Denial: Double Standards}

Denial, as noted above, can also be understood from a psychological perspective as the refusal to recognize an unpleasant reality. This unpleasant reality is the existence of double standards in the present nuclear order. A coarse engagement in the double standards debate can easily lead to an unhelpful conclusion

10) Hibbs (2011:3) argues that the interpretation of the new guidelines by Brazil and other NSG members is that Brazil and Argentina must not have Additional Protocols in place for ENR transfers. However, he notes that it is unlikely in practice that any current holder of sensitive material will supply Brazil or Argentina indefinitely without Additional Protocols in place. Although in theory there is leeway for other ABACC type arrangements in the new guidelines, those in the arms control community doubt that such arrangements will lead to the actual transfer of sensitive nuclear material. 
that Non-Nuclear Weapon States were duped into signing onto a discriminatory treaty (the NPT) that somehow institutionalizes into infinity "the right" of the P5 (or their allies) to possess nuclear weapons while excluding other states. This is not the engagement for which this article aims; rather, the article aims to explain how states can exercise agency despite these double standards by referring to South Africa's diplomacy in the NSG.

At this point briefly referring to some International Relations theory may help the engagement the article seeks to achieve. In E.H. Carr's (1962) seminal work The Twenty Years' Crisis 1919-1939: An Introduction to the Study of International Relations published in 1939, he notes: “... there is a stage where realism is the necessary corrective to the exuberance of utopianism, just as in other periods, utopianism must be invoked to counteract the barrenness of realism. Immature thought is predominantly purposive and utopian. Thought which rejects purpose is thought of old age... Utopia and reality are thus the two facets of political science. Sound political thought and sound political life will be found where both have their place" (Carr 1962: 10). In an interpretation of this statement, Kubalkova (1998) draws attention to the dialectic nature of idealism and realism in the politics that Carr describes as "sound". Carr related realism to idealism dialectically: idealism as thesis, realism as antithesis. He calls idealist (or utopian) campaigns hollow and intolerable shams that merely disguise the interests of the privileged and must be unmasked by realism, “... but pure realism can offer nothing but a naked struggle for power which makes any kind of international society impossible" (Carr 1962: 87). Realism is a transition to another utopia, "which as soon as it crystallizes itself in concrete political form, becomes tainted with self-interest and hypocrisy, and must once more be attacked with the instruments of realism" (ibid.). Some argue that Carr's dialectic approach to international order makes him a "proto' constructivist" (Kubalkova 1998: 25). International order spirals towards ideals, but turns from its "naiveté" towards institutions (or "reality"), until living under "sterile" facts becomes too barren and history turns once again to utopian ideals, and all the while this history spirals between the antithetic pair, international society is constructed.

The NPT Preamble captures the ideals (or spirit) of non-proliferation- general and complete disarmament and access to nuclear technology for peaceful purposes. However, Dan Joyner (2011) describes how the Nuclear Weapon States have consistently since the Cold War interpreted the NPT in such a way that disproportionately prioritizes the non-proliferation pillar of the Treaty, and deemphasizes the civilian energy development and disarmament pillars of the NPT. This interpretation has provided a legal grounding for policies related to trade in civilian nuclear energy technologies and nuclear weapons disarmament, which "Circumscribe the rights of non-nuclear-weapon States under Article IV of the Treaty by imposing conditions on the supply of civilian nuclear technologies. 
They also provide for the renewal and maintenance, and in some cases, further development of the nuclear weapons arsenals of nuclear-weapon States" (Joyner 2011).

The unpleasant reality is that in the 43 years since the NPT entered into force the Nuclear Weapon States have in practice (as opposed to rhetoric) not moved any closer to "[pursuing] negotiations in good faith on effective measures relating... to nuclear disarmament, and [towards] a Treaty on general and complete disarmament under strict and effective international control" (NPT 1970: Article VI). Although there are different opinions on whether Article VI of the Treaty implies actual nuclear disarmament or merely a commitment to pursue negotiations on disarmament and whether bilateral and unilateral steps of reduction in nuclear arsenals really meet Article VI obligations, the point is that the Nuclear Weapon States have been renewing their nuclear weapon systems (or have explicitly committed to it) and this shows no intention to bring a treaty on complete disarmament to conclusion. If not for all actors in the nuclear field, then at least for the Non-Aligned Movement, this qualifies as a breach of the NPT. Exposing the overemphasis on Non-Nuclear Weapon States' obligations by the Nuclear Weapon States, while themselves in breach of the NPT, is thus at the bottom of NAM's objections to further restrictions on ENR transfers.

A presentation that Ambassador Abdul Minty made at an international symposium on Highly Enriched Uranium (HEU) in 2006 provides insight into South Africa's position as well as an example to illustrate the link that the NAM makes with the disarmament obligation of Article VI. He asserted that addressing threats to collective security cannot only be directed exclusively at "reducing reliance on HEU for peaceful purposes, without any real commitment and progress on the elimination of HEU and other fissile materials that are primarily being used for military purposes" (Minty 2006:2). HEU is uranium enriched to more than 20\% $\mathrm{U}^{235}$ or $\mathrm{U}^{233}$ and is therefore considered "sensitive nuclear material." Minty also noted: "While we acknowledge the increasing importance of adequate controls over legitimate peaceful nuclear activities, especially in view of current realities, these must be matched by both the reinforcement of the obligation to achieve nuclear disarmament and by concrete, irreversible, and verifiable action in that direction, based on the consensual 13 practical steps as agreed upon in 2000" (Ibid.). The restriction of sensitive material is thus linked directly and indirectly to the Nuclear Weapon States' obligations, not only to give up their nuclear weapons as an end state, but to halt production of and reduce inventory of fissile material.

Raising the double standards of Nuclear Weapons States is not simply political rhetoric. In the realm of restricting sensitive technology and material, double standards have a direct commercial implication for emerging suppliers and, in the case under investigation, for South Africa. South Africa's SAFARI 1 reactor is one of the world's five major producers of medical isotopes for nuclear medicine diagnostics; the others being Canada's NRU, the Netherlands' HFR, 
Belgium's BR-2, and France's Osiris. Conversion of SAFARI 1 from producing Highly Enriched Uranium to Low Enriched Uranium (LEU) fuel was completed in 2009, but the South Africans went further to develop technology that uses LEU-based targets for isotope production. The economics of this move has been a concern with an increase of $20 \%$ in the cost of producing these isotopes from LEU. More uranium is used, which also has to be irradiated two to five times more and the process results in more uranium waste that must be handled. At the 2010 World Nuclear Association Symposium, Rob Adam, then CEO of the South African Nuclear Energy Corporation (Necsa), asserted that the radioisotope market is so depressed that it is not able to attract new investors (World Nuclear News 2010). Although the United States provided South Africa with $\$ 25$ million for the conversion of HEU to LEU use, most of the cost to develop LEU-based target technology was carried by the South African tax payer. The problem is not only that proliferation proofing is resulting in South Africa incurring higher costs, but that the other major producers have not followed suit to level the playing field. South Africa is thus competing against lower-cost HEU using producers. In a recent article of the Bulletin of Atomic Scientists, Miles Pomper and William Potter (2010) note, "As the self-proclaimed - and actual leader in combating nuclear terrorism, the Unites States must get its own act together [by adopting legislation that prohibits the US exports of HEU and commits the domestic US suppliers to LEU]. It cannot preach to other countries about the need to convert research reactors and medical isotope production to LEU when it fails to provide incentives to encourage that development."

The double standards are even starker when considering that the U.S. Energy Department's Reduced Enrichment for Research and Test Reactors (RERTR) program has converted dozens of reactors around the world from HEU to LEU while shutting down other underutilized HEU facilities.

In this sense, the two separate politics of (1) refusing Non-Nuclear Weapon States sensitive nuclear material and (2) refusing to acknowledge that Nuclear Weapon States have not met their obligations under the NPT, slip into one another. Ambassador Minty (2006:3) expressed the caution that: "The uncovering of a number of real or suspected cheaters and the prospect of weapons of mass destruction falling into the hands of non-State actors or terrorists should not become a pretext to curtail bona fide, lawful programs or scientific or commercial interest of developing countries."

Although the Non-Aligned Movement position is usually regarded as an idealist position, when we consider Carr's role for realism, it rather seems that the NAM wants to expose the hidden interest and double standards connoted by the "laudable" non-proliferation measure of making the Additional Protocol a condition of supply of ENR transfer. For seven years the pursuit of nuclear equity stalled negotiations in the NSG, a deadlock broken by the deal made with Brazil and Argentina that isolated South Africa. South Africa had two options: to stick 
to a principled position and comply with the NAM ideals of nuclear equity (i.e. refusing additional restrictions on Article IV rights) or South Africa could drop its objection under U.S. pressure and play along with the double standards that the ABACC exception implied. In the end, South Africa did a bit of both and was able to navigate a diplomatic quagmire to ensure an outcome that could in some way be justified to NAM, but still furthered non-proliferation aims. South Africa's diplomacy in the NSG reflected pragmatism and principle and, as such, can be placed at that turning point in the dialectic between realism and idealism where actors design an outcome that they "can live with."

\section{Conclusion}

This article set out to investigate what was described as South Africa's somewhat peculiar position, when South Africa took quite a strong stance against introducing the Additional Protocol as a condition of supply for sensitive nuclear technology and material to the NSG's guidelines. South Africa's NAM membership explains its objection. NAM sees the Additional Protocol condition as part of a bigger agenda to restrict access to ENR technology and, as such, to deny Non-Nuclear Weapon States their Article IV rights to all sorts of nuclear technology (including the sensitive kind). NAM also sees these restrictions as but another manifestation of the Nuclear Weapon States' over-prioritization of the non-proliferation leg of the NPT and their denial that the disarmament and civil technology legs of the NPT are equally important - and legally binding. When the powerful states in the NSG struck a deal with Brazil and Argentina, which essentially let both of them off the Additional Protocol hook, South Africa, in order to escape the "obstructionist" label, shifted to a position that at least allowed it to negotiate text that made the Brazil and Argentina exception less stark. In theory, the new text also opened legal space for states, otherwise in good standing with the IAEA, such as Egypt, to negotiate an IAEA approved arrangement similar to that of ABACC with Non-Nuclear Weapon States without an Additional Protocol, which would allow export of sensitive material on the same principle. The article used the lens of the politics of denial to show the nature of politics that played itself out in this arena of the nuclear order. It aimed to show how South Africa exerted its agency in the NSG and negotiated an outcome that serves pragmatism and principle in a way that arguably qualifies in Carr's term as "sound politics."

Although not the focus of this article, the politics of denial that played itself out in the NSG provokes thinking about when denial plays a positive or negative role in international negotiations. For example, when is a blanket denial (such as the Bush Administration's original position of restricting ENR technology to states already in possession of ENR facilities) workable and when is it a nonstarter that could stall negotiations indefinitely? In this case, the role of allies in 
negotiations is highlighted. The United States had to give way to a more permissive, criteria-based approach promoted by its own allies (France) to progress on stricter rules for ENR transfers in the NSG. Furthermore, under what conditions and for whom can denial be relaxed? Here the standing of objectors and the negotiating forum's rules are highlighted. The United States had to make deals with the three Non-Nuclear Weapons States objecting to the Additional Protocol. Brazil, Argentina, and South Africa have significant standing, because of their nuclear histories and as regional powers in the non-proliferation realm, and could not just be coerced to accept the denial that the Additional Protocol implied. The NSG's decision-making rules (by consensus) dictated that the US had to soften its denial to reach an acceptable outcome. In turn, how can "turning a blind eye" or denial in its psychological usage be employed in negotiations? The NSG negotiations on the Additional Protocol provide a precedent for states to negotiate situations where an obviously sensible measure is proposed by an actor (or actors), themselves in the wrong, making the proposed measure smack of hypocrisy and, therefore, difficult to accept despite its sensibility. South Africa relaxed its strong view, informed by its membership of the Non-Aligned Movement, that the Additional Protocol was linked to the Nuclear Weapons States' denial of their disarmament obligations. This allowed South African diplomats to reframe the Additional Protocol issue in terms of double standards within its own ranks (the Argentina and Brazil exception) and thus negotiate text that conformed to stronger restrictions of ENR technology whilst still acceptable to itself and the Non-Aligned Movement. Denial employed as the act of saying no or turning a blind eye to unpleasant realities is a negotiating tool in the diplomat's tool box; if skillfully employed and adapted to the situation, denial can move negotiations to acceptable conclusions.

\section{References}

AFP (2007). "SAfrica out of GNEP to keep right to enrich uranium: minister." 18 September. Available at: http://afp.google.com/article/ALeqM5iVN6X3NLfzljt66R_ThfRyFl6R2Q.

Brazilian-Argentine Agency for Accounting and Control of Nuclear Materials (n.d.). Nuclear Threat Initiative. Available at: http://www.nti.org/treaties-and-regimes/brazilian-argentineagency-accounting-and-control-nuclear-materials-abaccl

Carlson, J. (2011). "Letter to the editor: Additional Protocol as a condition of nuclear supply." Arms Control Today. March. Washington, DC: Arms Control Association.

Carr, Edward H. (1962). The Twenty Year's Crisis 1919-1939: An introduction to the study of International Relations. London, United Kingdom: Macmillan and Co.

El Baradei, Mohamad (2011). Age of Deception: Nuclear diplomacy in treacherous times. New York: Metropolitan Books.

Hibbs, Mark (2010). "Nuclear Suppliers Group and the IAEA Additional Protocol." Nuclear Energy Brief. 18 August. Washington, DC: Carnegie Endowment for International Peace. Available at: http://carnegieendowment.org/2010/08/18/nuclear-suppliers-group-and-iaea-additionalprotocol/1j71. 
(2011). “New Global Rules for Sensitive Nuclear Trade.” Nuclear Energy Brief. 28 July. Washington, DC: Carnegie Endowment for International Peace. Available at: http:// carnegieendowment.org/2011/07/28/new-global-rules-for-sensitive-nuclear-trade/4avp.

Hirsch, T. (2004). "The IAEA Additional Protocol: What it is and why it matters?" The Nonproliferation Review 11,3: 140-166.

Horner, D. (2011). "NSG Revises Rules on Sensitive Exports." Arms Control Today. July/August. Available at: http://www.armscontrol.org/act/2011_\%2007-08/Nuclear_Suppliers_Group_ NSG_Revises_Rules_Sensitive_Exports.

International Atomic Energy Agency (2003). "Safeguards Techniques and Equipment." International Nuclear Verification Series 1. Available at: http://www-pub.iaea.org/MTCD/publications/ PDF/NVS1-2003_web.pdf.

International Atomic Energy Agency (n.d.). "What we do.” Available at: http://www.iaea.org/ OurWork/SV/Safeguards/what.html.

Joyner, Daniel. H. (2011). Interpreting the Nuclear Nonproliferation Treaty. Oxford, United Kingdom: Oxford University Press.

Kerr, Paul K., Mark Holt, and Mary Nikitin (2011). "Nuclear Energy Cooperation with Foreign Countries: Issues for Congress." Congressional Research Service. August 10. Available at: http:// fpc.state.gov/documents/organization/171374.pdf.

Kimball, D. (2012). "The IAEA Additional Protocol at a glance." Arms Control Association. December. Available at: http://www.armscontrol.org/factsheets/IAEAProtoco.

Kubalkova, V. (1998). "The Twenty Years' Catharsis" in V. Kubalkova, N. Onuf and P. Kowerts, editors, International Relations in the Constructed World. Armonk, N.Y.: M.E. Sharpe.

Leith, R and J. Pretorius (2010) "Eroding the Middle Ground: The Shift in Foreign Policy Underpinning South African Nuclear Diplomacy.” Politikon 36, 3: 345-361.

Lewis, J. (2011a). "Greetings from Bruxelles!," Arms Control Wonk. 8 May. Available at: http:// lewis.armscontrolwonk.com/archive/3948/greetings-from-bruxelles.

_ (2011b). “Additional Protocol and ENR Transfers." Arms Control Wonk. 13 May. Available at: http://lewis.armscontrolwonk.com/archive/3962/additional-protocol-and-enr-transfers.

Marzo, M. (2012). "Additional Protocol: logic and impact." Brazilian-Argentine Agency for Accounting and Control of Nuclear Energy. Available at: http://www.abacc.org.br/wp-content/ uploads/2012/01/Additional-Protocol_Marzo.pdf.

McGoldrick, Fred (2011). Limiting Transfers of Enrichment and Reprocessing Technology: Issues, Constraints, Options. Cambridge, MA: Project on Managing the Atom, Belfer Center for Science and International Affairs, Harvard Kennedy School. Available at: http://belfercenter.ksg.harvard. edu/files/MTA-NSG-report-color.pdf.

Minty, A. (2006). "South African Perspectives on Highly Enriched Uranium (HEU). Statement at the International Symposium on Highly Enriched Uranium (HEU)," International Symposium on Highly Enriched Uranium. Oslo, Norway, 19-20 June. Available at: http://www.nrpa.no/ symposium/documents/Minty\%20HEU\%20Oslo\%20June\%202006.pdf.

- (2010). "Statement by Ambassador Abdul S. Minty, Special Representative for Disarmament and Nepad at the South African Department for International Relations and Cooperation, during the General Debate of the 2010 Review Conference of Parties to the Treaty on the NonProliferation of Nuclear Weapons." 5 May. New York. Available at: http://www.un.org/en/conf/ npt/2010/statements/pdf/southafrica_en.pdf.

Nassauer, O. (2006). "Nuclear energy and proliferation" in Nuclear Power: Myth and Reality. Saxonwold, South Africa: Heinrich Boll Foundation.

Nuclear Suppliers Group (2004). "The NSG - strengthening the nuclear non-proliferation regime." NSG Plenary Meeting. 27-28 May. Goteborg, Sweden. Available at: http://www.nuclearsuppliers group.org/Leng/PRESS/2004-05-goteborg.pdf. 
Permanent Mission of South Africa to the United Nations. (2010). "Statement by Ambassador Abdul S. Minty, Special Representative for Disarmament and NEPAD at the South African Department for International Relations and Cooperation during the General Debate of the 2010 Review Conference of Parties to the Treaty on the Non-Proliferation of Nuclear Weapons.” 5 May. New York. Available at: http://www.un.org/en/conf/npt/2010/statements/pdf/ southafrica_en.pdf.

Pomper, M.A. and W.C. Potter (2010). "Medical isotope production: The US must follow South Africa's lead”. Bulletin of Atomic Scientists. 17 December. Available at: http://thebulletin.org/ web-edition/features/medical-isotope-production-the-us-must-follow-south-africas-lead.

Pretorius, J. (2011). “The non-proliferation export norm and the 123 Agreement." Indian Journal of International Law 51:81-99.

Stockholm International Peace Research Institute (n.d.). "The no-undercut principle - Information exchange procedures." Available at: http://archives.sipri.org/contents/expcon/noproc.html.

The White House (2004). "Bush Urged International Action Against Spread of WMD." Washington, DC. 11 February. Available at: http://iipdigital.usembassy.gov/st/english/texttrans/2004/ 02/20040211174755ssorw8.063906e-02.html\#axzz2bIfRQx9l.

World Nuclear News (2010). "South African radioisotope production on target." 17 September. Available at: http://www.world-nuclear-news.org/RS-South_African_radioisotope_production_ on_target-1709107.html.

Yew, Y. (2011). "Diplomacy and Nuclear Non-proliferation: Navigating the Non-Aligned Movement Discussion Paper 2011-07." Cambridge, Massachusetts: Belfer Center for Science and International Affairs, Harvard University. 
